\title{
POLÍTICAS PÚBLICAS DE ESPORTE E LAZER NO BRASIL E POSSIBILIDADES DE INTERSETORIALIDADE ${ }^{1}$
}

Recebido em: $22 / 11 / 2012$

Aceito em: 20/04/2013

\author{
Sandra Aparecida Zotovici ${ }^{2}$ \\ Beatriz Ruffo Lopes ${ }^{3}$ \\ Renato Rangel ${ }^{4}$ \\ Fernando Augusto Starepravo 5 \\ Larissa Michelle Lara ${ }^{6}$ \\ Universidade Estadual de Maringá - UEM \\ Maringá - Paraná - Brasil
}

RESUMO: Este ensaio discorre sobre a trajetória das políticas públicas de esporte e lazer no Brasil e suas potencialidades para a intersetorialidade, bem como aponta as especificidades da realidade brasileira inerentes aos programas já existentes, a partir de uma leitura crítica da literatura disponível na área de educação física e ciências políticas. Tal intuito deu-se por um percurso histórico que recorreu a fatos da primeira Era Vargas até o Governo Lula, atrelados a apontamentos decorrentes de incursões pela literatura e de análises relacionadas às políticas públicas de esporte e lazer e políticas intersetoriais. Ante o investigado, aponta-se a intersetorialidade como perspectiva que pode dinamizar investimentos e atitudes que venham a priorizar o direito ao esporte e lazer como bem cultural.

PALAVRAS CHAVE: Esportes. Atividades de Lazer. Políticas Públicas.

\section{PUBLIC POLICIES FOR SPORT AND LEISURE IN BRAZIL AND POSSIBILITIES OF INTERSECTORIALITY}

ABSTRACT: This essay is concerned about the trajectory of the public policies for sport and leisure in Brazil and its possibilities of intersectoriality, pointing specificities about the brazilian reality inherent to the existing programs, based on a critical reading of the available physical education and political sciences literature. This aim came thru

\footnotetext{
${ }^{1}$ Todos os autores desse texto integram o Grupo de Pesquisa Corpo, Cultura e Ludicidade, vinculado ao Departamento de Educação Física da Universidade Estadual de Maringá (UEM) e ao Programa de PósGraduação Associado em Educação Física da UEM e da Universidade Estadual de Londrina (UEL).

${ }^{2}$ Doutoranda no Programa de Pós-Graduação Associado em Educação Física UEM/UEL - Bolsista CAPES.

${ }^{3}$ Mestranda no Programa de Pós-Graduação Associado em Educação Física UEM /UEL.

${ }^{4}$ Mestrando no Programa de Pós-Graduação Associado em Educação Física UEM/UEL.

${ }^{5}$ Programa de Pós-Graduação Associado em Educação Física UEM/UEL e Departamento de Educação Física - UEM.

${ }^{6}$ Programa de Pós-Graduação Associado em Educação Física UEM/UEL e Departamento de Educação Física - UEM.
} 
an historical course, which turned to facts from the first Vargas Era until Lula's government, culminating with notes due to incursions through literature and critical analyses related to the public policies for sport and leisure and intersectorial policies. Based on this research, the intersectoriality is pointed out as a perspective which can boost investments and attitudes that will prioritize the right to sport and leisure as a cultural property.

KEYWORDS: Sports, Leisure Activities. Public Policies.

\section{Introdução}

A problematização das políticas públicas de esporte e lazer ${ }^{7}$ suscita amplo debate sobre as políticas intersetoriais por meio do desenvolvimento de ações conjuntas de vários setores, visando atender às aspirações sociais dos envolvidos no processo. Assim, por mais que esse tema seja recorrente no debate contemporâneo sobre políticas públicas, entendemos que ele não alcança seu esgotamento ou saturação em função das diversas contribuições de cunho teórico e/ou prático que, mediante fatos novos, suscitam sempre intenso envolvimento da comunidade interessada.

No intuito de aprofundamento temático, esse ensaio tem por objetivo discorrer sobre trajetórias das políticas públicas de esporte e lazer no Brasil e suas possibilidades de intersetorialidade a partir de incursões teóricas. Para esse delineamento foram realizados identificação e seleção crítica de produções disponíveis na área de educação física e ciências políticas, seguido da revisão de cunho científico com interpretação, análise e síntese com vistas a perceber como a intersetorialidade acontece e se concretiza na gestão pública. Para tanto, retomamos percursos investigativos desenvolvidos por profissionais que tratam dessa temática, o que permitiu-nos compor a teia argumentativa dessa discussão.

\footnotetext{
7 Embora esporte e lazer sejam fenômenos distintos, o fato do Estado tratá-los, em geral, como equivalentes, assim como a produção científica da área, que normalmente aborda os dois objetos em conjunto, optou-se em trabalhá-los simultaneamente, e em suas aproximações. Seus distanciamentos, porém, serão também destacados no decorrer do texto.
} 
Estudiosos das políticas educacionais, como Goulart (2008), Knopp (2008) e Comerlatto et al (2007) veem como apologias as ações e manutenção do sistema das políticas públicas já existentes, as quais podem ampliar seus horizontes a partir de um olhar intersetorial, uma vez que as necessidades básicas para uma vida digna estão normatizadas por lei como direito de todo cidadão, envolvendo saúde, educação, saneamento básico, segurança, esporte e lazer. No que tange às questões funcionais no ciclo de política presente, questionamos se há espaço para a intersetorialidade, como se dá o entendimento do termo intersetorialidade e como ela acontece na perspectiva das políticas públicas de esporte e lazer.

Para o alcance do objetivo traçado para esse texto, dois tópicos orientam as reflexões que nos propusemos a desenvolver. No primeiro, houve a necessidade de articulação de elementos da primeira Era Vargas até o Governo Lula com os dados da agenda pública brasileira, o que nos auxiliou na identificação das políticas públicas de esporte e lazer em vigor no Brasil e os seus desdobramentos. No segundo, fez-se necessário o entendimento do ciclo da política, configurado na ação do planejamento e estratégias que visam a atender à demanda da agenda política, além de reconhecer o esporte e o lazer como foco de intervenções intersetoriais existentes no contexto das políticas públicas.

\section{Políticas públicas de esporte e lazer: aspectos históricos e agenda pública no Brasil}

O esporte e o lazer no Brasil ganham ênfase nas últimas décadas do século XX e primeiras décadas do século XXI devido à sua constituição histórica, reconhecimento social e, sobretudo, valores culturais que emanam, acrescido de formação ética para a cidadania. Há, portanto, o reconhecimento social do esporte e lazer como áreas de 
conhecimento e de intervenção social, cujas questões que permeiam esses aspectos tomam visibilidade e se ampliam juntamente com as iniciativas das autoridades que propiciam discussões no sentido de propor mudanças e avanços. Nesse contexto, argumentos corroboram que,

\begin{abstract}
A presença do esporte o do lazer como direitos sociais trouxe como uma das suas consequências a aprovação do Regulamento Geral da Conferência Nacional do Esporte. Assim a Conferência Nacional do Esporte carregando em sua essência a democratização do acesso ao esporte e ao lazer e, para tal, propôs princípios e diretrizes voltados à elaboração da Política Nacional do Esporte e Lazer. Outro desdobramento foi a criação do Sistema Nacional de Esporte e Lazer, cujo princípio fundamental é o regime de colaboração efetiva entre União os Estados e municípios, sendo enfáticos no que diz respeito à municipalização (DIAS; FONSECA, 2011, p.14-15).
\end{abstract}

O panorama das políticas públicas no contexto brasileiro é marcado por transformações, pois “[...] as últimas décadas registraram o ressurgimento da importância do campo de conhecimento denominado políticas públicas, assim como das instituições, regras e modelos que regem sua decisão, elaboração e implementação e avaliação [...]” (SOUZA, 2006, p.20), cujas implicações também se deram no âmbito do esporte e do lazer.

O cenário que abrange o desenvolvimento da agenda pública brasileira tem seu marco na revolução de 1930, período politicamente delineado pela Primeira Era Vargas (1930-1945). Esse período, considerado como a era do corporativismo orgânico, teve por princípio organizador das políticas públicas a integração e o nation building ${ }^{8}$ que teria como resultado a "[...] incorporação tutelada das massas urbanas à sociedade oligárquica; a construção de uma ordem institucional que permitisse a incorporação dos novos atores à arena política [...]” (MELO, 1998, p.12).

\footnotetext{
${ }^{8}$ Gomes (2009) elucida que obras literárias fazem uso do termo nation-building no sentido de "construção de nações" a partir de uma linha investigativa que tem por privilégio os diferentes processos de construção estatal. $\mathrm{O}$ autor ressalta aspectos que envolvem a relação entre Estado e sociedade e aponta a relevância dos conflitos e guerras para a formação dos países, bem como o poder que o capitalismo tem de influenciar no que diz respeito à expansão da entidade política, representada como Estado pelo mundo.
} 
Em 1941, o primeiro documento legal sobre o esporte é elaborado - Decreto Lei $\mathrm{n}^{\mathrm{o}} 3.199 / 41$ - com apoio nos subsequentes Decretos $\mathrm{n}^{0 .} 9.267 / 42$ e $\mathrm{n}^{0 .} 7.674 / 45$, bem como nas diversas deliberações do Conselho Nacional de Desporto (CND) no intuito de “disciplinar e pacificar o esporte brasileiro” (CASTELLANI FILHO, 1999, p.32), isto é, restabelecer a paz, o espírito de disciplina e o patriotismo. Essa intenção nacionalista e pacificadora figurou durante todo o regime militar, cabendo ao CND a estruturação e o comando do esporte nacional até 1970.

\begin{abstract}
O próprio processo de intervenção do Estado no campo esportivo se deu muito mais por lógicas existentes no interior do próprio campo político/burocrático do que por uma reconhecida demanda da sociedade. Tão pouco, o esporte foi oficializado a partir da perspectiva do reconhecimento como um direito social, mesmo sendo esse um dos argumentos oficiais para intervenção (STAREPRAVO, 2011, p.199).
\end{abstract}

Esse jogo de interesses que acontece nas ações das políticas públicas faz com que a agenda seja muitas vezes organizada sem considerar amplamente as necessidades sociais. Historicamente, observa-se que algumas manifestações se transformaram em lucrativo produto de consumo no mercado do esporte e lazer no país, manipuladas pelo processo de mercadorização de bens culturais. Samba, futebol e carnaval, por exemplo, foram disponibilizados para a comercialização e deturpação dos sentidos/significados que os norteiam como arte, esporte e lazer, campos de conhecimento teorizados pela educação física e que podem ser refletidos pelos profissionais dessa área também por esse viés, ao se pensar em políticas públicas de esporte e lazer. Especificamente, o esporte fez parte do jogo político que envolveu os brasileiros como tentativa de desviar o foco da situação de opressão em que o país se encontrava no período do regime militar.

O carnaval que tomou conta do país, em 1970, com a conquista do tricampeonato mundial, era um paradoxo da dura realidade social. Afinal, em plena ditadura, a grande massa fazia o jogo político do governo e deixava de lado os porões das torturas e da censura do regime. O samba, as mulatas, o 
carnaval e o futebol assumiram visibilidade significativa na cultura brasileira, como produtos de exportação, cartão de visitas para estrangeiros e reconhecimento do Brasil no exterior (AZEVEDO, 2007, p.43).

A partir da criação do Ministério da Educação e Cultura (MEC) e do Departamento de Educação Física e Desporto (DED), surge o primeiro Plano de Educação Física e Desporto (PED), em 1971, e, na sequência, em 1975, a Lei Federal $\mathrm{n}^{\mathrm{o}} 6.251 / 75$ e o Decreto Lei $\mathrm{n}^{\mathrm{o}} 80.228 / 77$, responsáveis pela Política Nacional de Desenvolvimento da Educação Física e Desporto (PNDE), no período de 1976 a 1979. O esporte, caracterizado por acentuada conotação de rendimento, fortalece o caráter nacionalista do regime militar. Movimentos populares, sociais e políticos ganham força após o fim desse regime e as discussões culminaram na elaboração da Constituição Federal Brasileira (CFB) de 1988.

Das inúmeras mudanças, uma essencial foi ter o esporte e o lazer como direito de todo cidadão, como segue: “Art 217 - É dever do Estado fomentar práticas desportivas formais e não formais, como direito de cada um [...]”. (BRASIL, 1988, p.140). E ainda " $\S 3^{\circ}-$ O poder público incentivará o lazer, como forma de promoção social”. (BRASIL, 1988, p.140). O Art. $6^{\circ}$ também destaca o lazer como direito: "São direitos sociais a educação, a saúde, a alimentação, o trabalho, a moradia, o lazer, a segurança, a previdência social, a proteção à maternidade e à infância, a assistência aos desamparados, na forma desta Constituição [...]” (BRASIL, 1988, p. 20).

$\mathrm{Na}$ apresentação da agenda pública brasileira, realizada por Melo (1998), visualizamos o período do Governo Collor como uma fase que tem como princípio organizador de políticas públicas o Cesarismo Reformista, ou seja, reformas tidas como imperativos de governabilidade, os quais traduzem uma gestão que buscava “[...] a 
reestruturação ad hoc e pouco consistente das políticas: focalização, seletividade e redefinição do mix público-privado das políticas” (MELO, 1998, p.11).

Quando o esporte passa a figurar como parte da agenda pública, desvinculandose do MEC, cria-se a Secretaria de Desportos da Presidência da República que, por estar vinculada à estrutura da presidência, apresenta-se com status ministerial. Assim, os secretários que compunham essa organização eram o ex-jogador Zico, Arthur Antunes Coimbra (março e abril/1991) e Bernard Rajzman (abril/1991 a outubro/1992). Como relata Proni (2000), o esporte de alto rendimento necessitava de uma nova legislação que possibilitasse a modernização e a democratização das instituições esportivas, o que incentivou o encaminhamento ao Congresso Nacional, em 1991, do Projeto Zico, que se configurou na Lei Zico, $\mathrm{n}^{\mathrm{o}} 8.672 / 93$, destinada a:

i) regulamentar a presença de empresas e as formas de comercialização no futebol profissional, ii) rever a partição nos recursos da Loteria Esportiva, iii) extinguir a lei de "passe" e estabelecer uma nova norma para o contrato de trabalho do atleta profissional, iv) redefinir os mecanismos de supervisão e assegurar a autonomia estatutária dos clubes, assim como v) buscar mecanismos mais democráticos e transparentes de representação e de administração das federações e da CBF (PRONI, 2000, p.165).

Já no governo Fernando Henrique Cardoso (1995-2002) há novo princípio organizador da política pública, a partir das seguintes ações:

Instituir a Boa Governança; ação pública como fixação de regras do jogo estáveis e universalistas; primado da pobreza absoluta sobre a desigualdade no debate público que se tem por efeito esperado a focalização, seletividade e redefinição do mix público-privado das políticas; restaurar as bases fiscais das políticas; políticas compensatórias dos custos sociais da estabilização (MELO, 1998, p.12).

Em 1995, o então presidente cria o Ministério de Estado Extraordinário do Esporte, nomeando o ex-jogador de futebol, Edson Arantes do Nascimento, Pelé (19951998), como Ministro Extraordinário do Esporte. Como esclarece Proni (2000), mediante alguns obstáculos no entendimento do texto da Lei Zico, outro projeto de lei 
foi elaborado e encaminhado para aprovação, o qual foi muito criticado pelo presidente da Confederação Brasileira de Futebol (CBF) que, entre negociações e alterações, consegue sua aprovação. Assim é sancionada a Lei 9.615/98, mais conhecida como Lei Pelé.

Tanto a Lei Zico como a Lei Pelé têm explícito em seu projeto o anseio por benefícios ao futebol brasileiro. Porém, ambas apresentam fragilidades, pois não deram conta de atender às necessidades de controle no que diz respeito ao passe dos jogadores, haja vista o interesse por parte dos clubes e a intervenção da CBF. Porém, notamos que nesse período, a agenda pública do esporte de alto rendimento esteve centrada em políticas que atendiam prioritariamente às necessidades do futebol, deixando de lado outros esportes.

Em 2001, foi aprovada a Lei $n^{\circ} 10.264 / 2001$, também denominada Lei Agnelo Piva (BRASIL, 2005, p.14), que beneficiou as Entidades de Administração do Esporte, além de criar condições materiais que viabilizaram a possibilidade de agir com autonomia. Essa lei modificou a Lei Pelé no que diz respeito aos recursos destinados ao esporte e ampliou os percentuais destinados ao Comitê Olímpico Brasileiro (COB) e ao Comitê Paralímpico Brasileiro (CPB).

Dois anos mais tarde, com as Leis $n^{\circ} 10.671 / 2003$ e $n^{\circ} 10.672 / 2003$, conhecidas respectivamente como Estatuto do Torcedor, “[...] que estabelece normas de proteção e defesa com procedimentos e regras para os clubes, donos de estádios, dirigentes, bem como para os próprios torcedores [...]” (BRASIL, 2005, p.14), e Lei de Moralização dos Clubes "[...] que fixa regras de transparência para os clubes e dirigentes [...]" (BRASIL, 2005, p.14), percebemos que a pauta da política de esporte nos primeiros anos do novo 
milênio esteve centrada nas questões relativas ao financiamento do esporte de rendimento e às demandas do futebol.

O esporte passa por um período de valoração, o que acaba por culminar no início do governo Lula (2003), com a instauração do Ministério de Esporte (ME). "Sua criação representou um marco da relação entre o esporte e o Estado no Brasil, já que pela primeira vez na história, o esporte alcançou status de Ministério permanente e autônomo" (STAREPRAVO, 2011, p. 21). Assim, como a aliança formada com o PCdoB foi importante à consolidação desse ministério, Agnelo Queiroz foi convidado a ocupar o cargo de ministro, o qual estabelece as novas Secretarias de Esporte dentro dos parâmetros legais da Lei Pelé e da Constituição Federal: a) Secretaria Nacional de Esporte Educacional (SNEED); b) Secretaria Nacional de Desenvolvimento do Esporte e do Lazer (SNDEL); c) Secretaria Nacional de Esporte de Alto Rendimento (SNEAR).

Cada Secretaria se ocupou de um segmento do esporte e coube à SNEED e à SNDEL a realização dos principais programas do esporte como inclusão social, a saber, o Programa Segundo Tempo (PST) e o Programa Esporte e Lazer da Cidade (PELC). Como consta em documentos orientadores do PELC (BRASIL, 2012b), a intenção de garantir o esporte e o lazer como direito social a toda população remete ao fato de que o esporte, de forma isolada, não fazia sentido, o que levou à tentativa de integração das políticas públicas de esporte e lazer às políticas públicas da saúde, educação, assistência social, segurança, entre outras, por meio de ações intersetoriais.

Verificamos em documentos (BRASIL, 2011a) que esse diálogo acerca da intersetorialidade foi indicado nas três Conferências Nacionais de Esporte (CNE), ocorridas em 2004, 2006 e 2010, o que culminou na estruturação de documentos finais em que constam, por exemplo, Programas como PELC e Programa Nacional de 
Segurança Pública (PRONASCI), os quais remetem a possibilidades no caminho dessa ação conjunta intersetorial.

[...] a diretriz da intersetorialidade busca articular outros campos de atuação do poder público, como educação, segurança e cultura ao PELC. A expressão maior da intersetorialidade está presente na criação dos núcleos Pronasci/PELC a partir do ano de 2008, voltado ao enfrentamento da violência, especialmente para jovens de 15 a 24 anos, em uma ação que envolve o Ministério da Justiça, e nas ações do Esporte, Lazer e Educação Integral em parceria com o Ministério da Educação (STAREPRAVO, 2011, p. 278).

Filgueira (2009) explana sobre uma ação conjunta intersetorial, em que crianças e jovens participam do PST no contraturno escolar e aos finais de semana, com a oferta do esporte no tempo livre, o que justifica a inserção do programa no contexto do lazer. O esporte e a educação partem do princípio do corpo histórico, cujas práticas corporais são representativas, com significado único para cada sujeito, inserindo-se como processos educacionais e culturais que possibilitam a construção da gestualidade corporal. Como lembram o Art. 6 e o Art. 217, da Constituição Federal Brasileira (1988), esporte e lazer são direitos de cada cidadão e, por isso, devem ser garantidos pelo Estado. Nessa linha argumentativa, Hassenpflug (2004) discorre sobre a necessidade de convivência social pelo esporte e alicerça seu aprendizado na construção de valores, na promoção de saúde e, principalmente, no aprimoramento da consciência crítica e da cidadania.

Na gestão da presidenta Dilma Rousseff, a estrutura funcional das Secretarias do Ministério de Esporte foi modificada, levando a SNDEL a ser dissolvida e incorporada à SNEED, a qual modificou sua nomenclatura para Secretaria Nacional de Esporte, Educação, Lazer e Inclusão Social (SNELIS). Nessa nova estrutura, cria-se a Secretaria Nacional de Futebol e Defesa dos Direitos do Torcedor, impulsionada pela realização da Copa do Mundo de 2014, no Brasil, e mantém-se uma única secretaria - a SNEAR - 
voltada ao alto rendimento. Tais fatos nos levam a identificar como pragmáticas e lamentáveis a destituição da SNDEL e as ações desarticuladoras de um sistema de política pública de esporte e lazer, iniciado em 2003, que se voltava para o atendimento a cidadãos comuns, ou seja, a uma parcela da população alijada do acesso a seus direitos. Mesmo em meio à escassez de recursos humanos e financeiros, essa secretaria desenvolveu ações pautadas por uma motivação intersetorial, com o engajamento de pesquisadores, comunidades e gestores públicos, motivados pela pesquisa (Rede Cedes $^{9}$ ) e pela intervenção social em diferentes realidades.

Dada a carência de um plano nacional de esporte e lazer por parte do Governo Federal, que transcenda finalidades imediatistas e transitórias, como a Copa do Mundo de 2014, a população vive, e nem sempre de modo consciente, a escassez de ações que possibilitem o acesso ao direito a práticas esportivas e de lazer. Isso porque, a incorporação da SNDEL (ou parte dela, dada a destituição quase por completo da equipe de trabalho dessa secretaria) a uma secretaria já estruturada, como a SNEED, não se dá em proporções iguais (nem em recursos humanos e financeiros, nem em visibilidade). Mesmo se considerarmos a fase de transição e acomodação da SNDEL à SNEED, não há como ignorar sua dificuldade evidente em dar continuidade aos projetos já existentes e a implementar outros projetos. Num país sem tradição em planejamento esportivo e de lazer com vistas à democratização de sua prática, e ainda, com poucas experiências na organização de megaeventos esportivos, a criação de uma secretaria específica do futebol é algo, no mínimo, desconfortável, considerando as várias modalidades esportivas que atualmente integram a tradição cultural brasileira, mesmo

\footnotetext{
${ }^{9}$ Starepravo (2011) relata que há destaque para o início do ME, em 2003, e para a Rede Cedes, por seu efeito multiplicador, com participação de alunos de Iniciação Científica, formação de grupos de estudo e de pesquisa, os quais proporcionaram salto quantitativo em produção científica relacionada às políticas públicas no Brasil.
} 
com o papel de destaque que o futebol do Brasil obteve, sobretudo em termos de representação no cenário mundial.

Tubino (2010) discorre sobre as políticas públicas do esporte no Brasil, relatando que o sistema não acompanhou a realidade nacional do esporte, momento em que passa a vigorar a Lei $n^{0 .} 9.615 / 1998$, regulamentada pelo Decreto $n^{0 .} 2.574 / 1998$. Para o autor, o sistema é um “[...] conjunto de partes em constante interação (interatuação e interdependência das partes) constituindo um todo sinérgico orientado para sentidos (propósitos e fins), com capacidades de influenciar o meio externo e por ele ser influenciado" (TUBINO, 2010, p.91). A seguir, a FIG. 1 apresenta a estrutura da política nacional de esporte pensada por Tubino (2010).

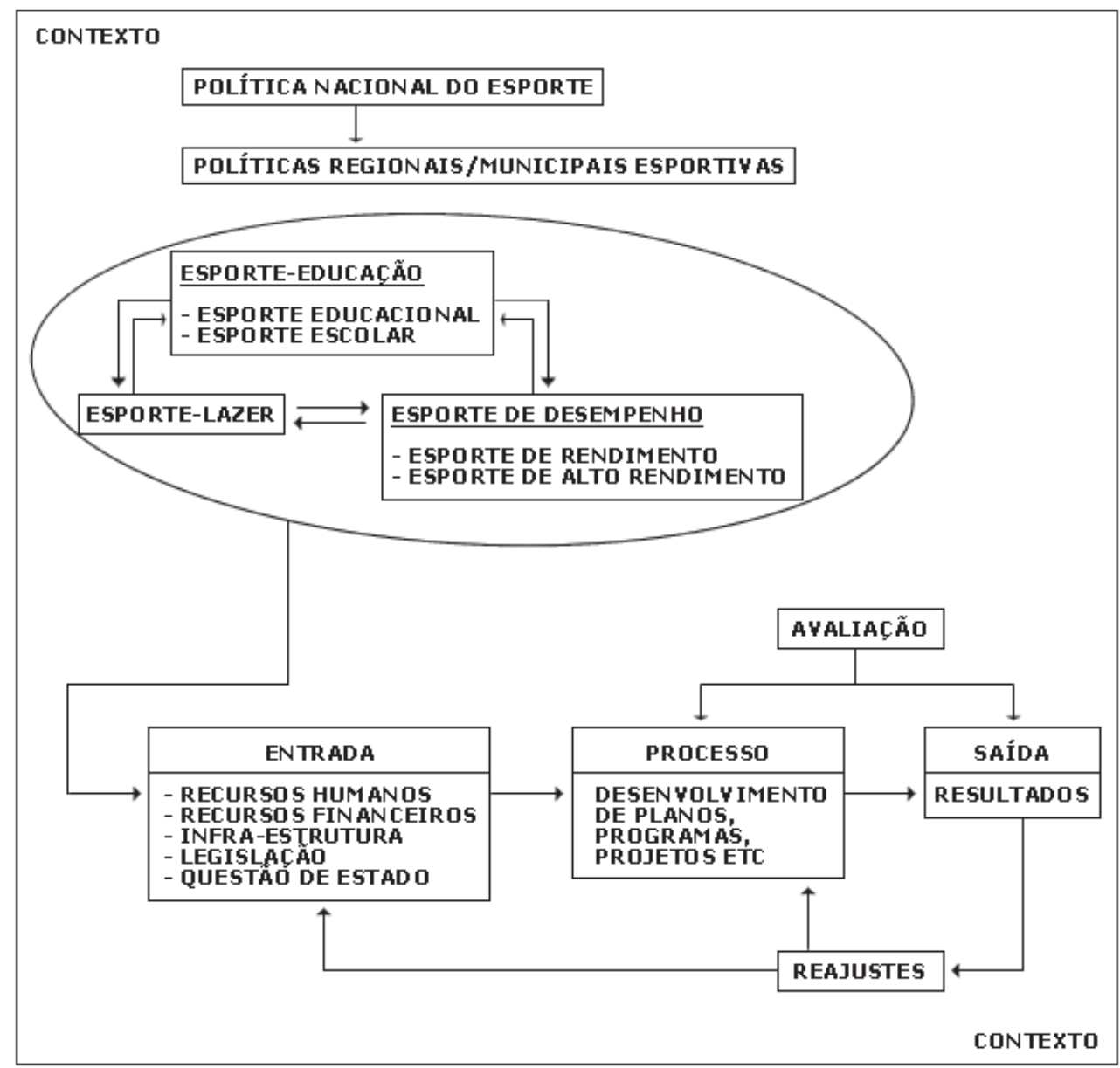

FIGURA 1 - Estrutura da Política Nacional do Esporte. (TUBINO, 2010, p.92). 
O autor julga como desatualizado o Sistema Brasileiro do Desporto (SBD), bem como o Sistema Nacional de Desporto (SND), sobretudo porque não conseguem atender às demandas do cenário nacional do esporte, haja vista que algumas dessas tentativas de modificação já acontecem desde a CNE (2006). Para Starepravo (2011, p. 101), “[...] o atual quadro social brasileiro demonstraria a necessidade de formulação e implementação de políticas sociais que estariam vinculadas a um projeto histórico de superação das desigualdades sociais [...]", projeto esse que fosse comprometido com a modificação do cenário de exclusão, injustiça e vulnerabilidade social. Isso indica que a demanda nem sempre é assistida ou inserida na agenda pública, seja pelo desinteresse político de atender às camadas que apresentem maior necessidade de centralizar ações, seja pela carência de uma gestão capaz de pensar na inclusão, na justiça e na democratização esportiva e de lazer.

\begin{abstract}
A política pública muitas vezes é apenas a parte mais visível de todo um processo desenvolvido num espaço social específico, que comporta disputas, relações, alianças, decisões estratégicas e também não planejadas. Em suma, escrever sobre políticas públicas de esporte e lazer requer mapear o espaço social onde está produzida, avançar e no entendimento das relações entre os agentes, até finalmente compreender quais as políticas que foram efetivadas, aquelas que foram preteridas, as que obtiveram êxito e aquelas que não passaram de propostas (STAREPRAVO, 2011, p.174-175).
\end{abstract}

A gestão do Governo Lula, na visão de Starepravo (2011), completou um ciclo político de oito anos da formalização institucional do ME, o qual veio a chamar a atenção de pesquisadores da área de políticas públicas de esporte e lazer, tema atualmente em destaque na esfera científico/acadêmica devido a algumas ações, como a criação de uma Rede (o autor se refere à Rede Cedes/ME ${ }^{10}$ ) que visa atender aos

\footnotetext{
${ }^{10}$ Informações históricas sobre ações da Rede Cedes podem ser consultadas em "Gestão da informação: sobre esporte recreativo e lazer: balanço da Rede Cedes", de Schartz et al (2010), obra resultante de uma pesquisa induzida pelo Ministério do Esporte que busca contextualizar a rede Cedes, mapear os produtos e desdobramentos das pesquisas financiadas pela rede, avaliar os impactos, as contribuições de gestores e pesquisadores no período de 2003 a 2010, bem como trazer reflexões acerca da produção da rede nesse período.
} 
interesses de pesquisa e implementação de políticas públicas, bem como, a participação aberta de diferentes grupos sociais para formulação dessas políticas, ou até, a ênfase dada à produção de megaeventos esportivos no país. Com base no desenvolvimento de sua tese de doutorado o pesquisador afirma que o subcampo científico/acadêmico constitui-se como “[...] espaço fundamental para a pretensa mudança nas políticas públicas de esporte e lazer no Brasil”' (STAREPRAVO, 2011, p. 321).

Diante do estímulo dado à produção científico/acadêmica, a qual demonstrou a necessidade de diálogo e interlocução entre fatos históricos e a disseminação de conhecimentos sobre as políticas públicas de esporte e lazer, podemos considerar que o cenário político brasileiro - foco de debates e discussões - trouxe como consequência a cobrança de ações determinantes que favoreceram a criação e a ampliação de metas e investimento em novos projetos e programas sociais.

\section{A intersetorialidade no cenário político brasileiro: aproximações com as políticas de esporte e lazer}

Até o momento discorremos de modo geral sobre políticas de esporte e lazer sem enunciar, especificamente, seus campos constitutivos particulares. Porém, como demarcado anteriormente, as ações no campo político na esfera do esporte e lazer têm sido pautadas no setor do esporte de alto rendimento e na ação do esporte como mecanismo salvacionista em articulação com diferentes políticas sociais.

O lazer tem sua trajetória marcada pela conotação político-temporal e acompanha tais transformações via passagem da forma compensatória atribuída aos trabalhadores da indústria, nas décadas de 1930 a 1950, para a conotação cultural que o envolve como item a ser garantido na busca de qualidade de vida, compondo os direitos 
sociais, em especial, na Constituição Federal de 1988 e no Estatuto da Criança e do Adolescente (ECA). Ao deixar de ser considerado benefício social e ser tratado como importante no processo de melhoria da qualidade de vida, no entender de Pinto et al (2011), o lazer passa a compor de forma significativa os textos de leis e políticas que reconhecem e protegem-no como direito constitucional.

Na sociedade hodierna, o lazer vislumbra status ministerial junto ao esporte e à parte significativa dos programas lançados pelo Ministério do Esporte em atendimento à demanda da sociedade. Esse ministério busca, ainda, harmonizar lazer e esporte, ou mesmo, torná-los sinônimos, como se ao incentivar a prática ao esporte, consequentemente, estimularia o lazer da sociedade. Contudo, entendemos que o lazer percorre outra trilha, qual seja, a de um elemento chave na valorização dos bens culturais em favor da emancipação, em que a dimensão do esporte representa um meio para tal conquista.

Mesmo com a intensificação dos debates na área do lazer como direito social nos últimos anos, tais ações efetivas não seguem a mesma lógica, conferindo ao esporte tal missão. Por meio do esporte, seja educacional ou de rendimento, as políticas públicas têm acontecido em articulação a outras esferas do poder público, o que não desprivilegia o lazer mas, pelo contrário, o tematiza como suporte operacional, a exemplo das políticas focadas nos megaeventos que tendem a deixar como legado as estruturas físicas e a prática esportiva como meio de promoção do lazer.

Na tematização da intersetorialidade no campo do esporte e do lazer procuramos dialogar com ações e metas propostas em cada CNE, as quais estabelecem a seleção específica de políticas públicas intersetoriais embora, em alguns momentos, surjam 
contrapontos a serem discutidos devido às divergências apresentadas em dados programas sociais.

A CNE de 2004 (BRASIL, 2005) trata do processo de construção e divulgação de políticas públicas, elaborada com a intenção de disseminar o conhecimento junto à comunidade esportiva e à sociedade em geral, bem como nortear o posicionamento e as deliberações que orientam e subsidiam a Política Nacional do Esporte e Lazer, implementadas pelo governo Lula, por meio do ME. Ao analisar seu documento final, observamos que o texto não apresenta a preocupação com políticas intersetoriais. Todavia, notamos que implicitamente a intersetorialidade se faz presente nesse documento, o qual indica, ainda, a urgência na ampliação da produção acadêmico/científico sobre o tema.

Nesse ínterim, mais um evento dá continuidade ao processo de implementação de políticas públicas intersetoriais, por meio do documento final que relata as ações que foram estimuladas pela CNE de 2006 em relação à intersetorialidade. Como consta na proposta aprovada em plenária final, apresentada no texto Eixo 1 - Estrutura: organização, agentes, competências, item 1,

O Sistema Nacional de Esporte e Lazer, tendo por base o regime de colaboração entre União, estados e municípios, com ênfase na municipalização, consolidando o esporte e o lazer como direitos sociais e guiando-se pelos princípios da demonstração e inclusão social, articula, integra, promove e estabelece relações éticas de parcerias entre as entidades da sociedade civil, instituições públicas e privadas, em torno do esporte educacional, de participação e de rendimento, valorizando a acessibilidade, a descentralização, a intersetorialidade e a multidisciplinaridade das ações esportivas e de lazer (BRASIL, 2007, p.19).

Ao analisar a CNE de 2010, percebemos que ela apresenta em sua proposta ações intersetoriais, como segue na linha três "Esporte, Lazer e Cultura", junto à ação dois, que indica a: "Ampliação e qualificação das ações intersetoriais dos Programas do Governo Federal" (BRASIL, 2011a, s/p). Seguem suas metas: 
1. Implantar e ampliar em $100 \%$ dos territórios PRONASCI os núcleos PRONASCI/PELC com faixa etária de 15 a 24 anos inclusive as pessoas com deficiência e mobilidade reduzida, com garantia que os beneficiários sejam atendidos por profissionais qualificados em suas respectivas áreas de atuação, de acordo com o mapeamento das demandas locais. 2. Instituir o Programa Segundo Tempo em 100\% das escolas do Programa Mais Educação - MEC, não sendo substitutivo da educação física enquanto componente curricular, conforme LDB 9394/96, garantindo o espaço físico para este. 3. Ampliar as parcerias intersetoriais com outros Programas sociais do Governo Federal em projetos educativos com conteúdos multidisciplinares, como a Escola Aberta (BRASIL, 2011a, s/p).

Pelos relatórios e propostas da CNE de 2010 (BRASIL, 2010), observamos demonstração de interesse por parte de seus organizadores e participantes no tocante ao incentivo das políticas intersetoriais, as quais não se constituem em motivo para substituição da educação física no contexto escolar, sobretudo porque representam questões distintas. Porém, sabe-se que sua concretização depende de ações que possam transcender palavras por meio de atitudes dos devidos gestores e órgãos públicos responsáveis, os quais precisam perceber a intersetorialidade como meio diferencial para viabilizar projetos sociais que possam beneficiar a população, essencial para o pleno desenvolvimento dos diversos setores das políticas públicas.

No campo do esporte e do lazer nos deparamos de forma singular com a intersetorialidade e, também, com o caráter salvacionista que os objetivos dos programas do ME parecem assumir. Aqui, tomamos a intersetorialidade como estratégia de gestão que aponta interdependências e dissemina redes educativas locais. Essas redes, com base em Junqueira (2000), Meirelles e Erdmann (2006) e Bronzo e Veiga (2007) constituem-se como sinal de interconexão, interdependência, estreitamento de relações de trocas e intercâmbios, ou seja, como condição necessária que procura abarcar a complexidade apresentada pelos processos educacionais e pela realidade social. 
No que se referem às políticas públicas no campo do esporte e lazer, nos propomos a refletir a noção rede como forma de integração e cooperação entre diferentes interlocutores no intuito de superar possíveis fragilidades existentes nesse campo. Assim, refletir sobre a organização das políticas públicas por meio das redes sociais é contemplar as múltiplas interconexões existentes nas relações dos sujeitos que estão envolvidos nesse processo.

Para Junqueira (2000), o conceito de rede representa formas de articular diversos atores sociais para criar conhecimentos e intervir. O autor enfatiza que é por meio das relações estabelecidas entre as partes que novas potencialidades são originadas, numa espécie de retroalimentação. Noutras palavras, o autor nos apresenta a ideia de superação de conhecimentos hierárquicos e fragmentados para valorização da complexidade social - tanto das partes quanto do todo - formando, assim, um todo complexo. Nas suas palavras (JUNQUEIRA, 2000, p. 39), "as redes, no universo de mudanças, surgem como uma linguagem de vínculos, das relações sociais entre organizações que interagem mediadas por atores sociais que buscam entender de maneira compartilhada a realidade social".

Para além da articulação entre os atores sociais e organizações, promovida pela rede, esse processo permite, também, uma nova maneira de analisar e entender a realidade social. Por isso, a rede pode resultar num saber intersetorial que viabilize a participação e democratização na tomada de decisão na gestão das políticas sociais: "Esta [ação intersetorial] é uma perspectiva importante, porque aponta para uma visão integrada dos problemas sociais e também para a sua solução" (JUNQUEIRA, 2000, p. 42). 
A gestão intersetorial se faz necessária dentro das políticas públicas e merece ser tratada de modo rigoroso, uma vez que pressupõe a ação coletiva e a proposta de pactuar conhecimentos, viabilizar ações, interesses, valores e estratégias.

\begin{abstract}
A intersetorialidade incorpora a ideia de integração, de território, de equidade, enfim dos direitos sociais; é uma nova maneira de abordar os problemas sociais. Cada política social encaminha a seu modo uma solução, sem considerar o cidadão na sua totalidade e nem a ação das outras políticas sociais, que também estão buscando a melhoria da qualidade de vida (JUNQUEIRA, 2004, p.27).
\end{abstract}

A articulação de saberes de diferentes áreas torna-se fundante no interior de uma política pública de esporte e lazer, uma vez que ela, sozinha, nem sempre consegue viabilizar adequadamente certas ações. A complexidade da sociedade atual, sobretudo quando diz respeito à melhoria das condições de vida das camadas pobres da sociedade, faz com que muitas políticas públicas sejam de difícil gestão, não acontecendo de forma conjunta. Nesse contexto, adverte Junqueira (2004), a ação intersetorial se faz relevante ao proporcionar uma nova forma de gestão das políticas sociais (agora integrada), e ao se preocupar com a população e com seus problemas circunscritos num território ou em uma região da cidade, ou município. O autor observa que nessa reflexão conjunta dos problemas sociais há, também, interesse pelo papel social do cidadão: "É uma nova lógica para a gestão da cidade, buscando superar a fragmentação das políticas, considerando o cidadão na sua totalidade" (JUNQUEIRA, 2004, p.27).

Entretanto, essa articulação política ainda não constitui uma prática comum entre os gestores, como observam Ckagnazaroff e Melo (2005, p. 2) ao ressaltarem alguns aspectos que determinam essa desintegração entre as políticas públicas:

Tal crítica se refere principalmente ao fato de que esses problemas são considerados de acordo com a especialização dos profissionais responsáveis pelo serviço sem envolvimento de outros setores. Em consequência a intervenção na realidade tende a ser insatisfatória seja em termos da capacidade de resolução seja em termos dos gastos incorridos. 
Essa problemática observada por Ckagnazaroff e Melo (2005) vai ao encontro da reflexão realizada por Bonalume $(2011$, p. 5) ao compreender que a fragmentação dos mais diversos setores da sociedade decorre de um processo histórico e "[...] parte do momento em que a sociedade passou a exigir e produzir mais conhecimento, o que levou ao surgimento de algumas áreas específicas, com o intuito de aprofundar esse saber - as especializações". Para a autora, nesse processo de aprimoramento dos saberes, a totalidade do cidadão passou a ser ignorada e embora na sociedade atual haja acesso a formações e informações, ainda não se superou a lógica fragmentada do conhecimento, fato esse que se reflete nas políticas públicas. Entende ainda que, no campo das políticas públicas do esporte e lazer, a intersetorialidade se delineia como um instrumento na construção de ações de democratização, as quais buscam superar algumas condições históricas vividas no Brasil:

\begin{abstract}
A intersetorialidade é um princípio que privilegia a integração matricial das políticas sociais, tanto na fase de planejamento quanto nas de execução, monitoramento e avaliação. Essa matricialidade representa o eixo coordenador e organizador dessas políticas, potencializando sua integração, com impacto positivo em seus efeitos. Isso implica planejamento e gestão compartilhada, ou seja, a construção de espaços de convergências de sujeitos que se completam à medida que se articulam esforços para atuar em prol de objetivos comuns (BONALUME, 2011, p. 13-4).
\end{abstract}

Envolver e relacionar outros campos de ação às políticas de esporte e lazer não é uma tarefa fácil, e um dos motivos dessa dificuldade é que, embora esse seja um assunto de intensas discussões na atualidade, as gestões de políticas de esporte e lazer ainda apresentam falhas nas ações e, em alguns locais, parecem ter encontrado empecilhos em sua consolidação. Suassuna et al (2007) enfatizam que há contribuições de outras áreas em relação à pesquisa em políticas públicas, mas que essas outras áreas trazem o enfoque em saberes como economia, saúde e educação, deixando de lado a discussão sobre esporte e lazer. Os autores ainda afirmam que, 


\begin{abstract}
Muito embora se admita a existência de atenção ao estudo do tema, há que se ressaltar que o grande debate proposto pelas diferentes áreas dedica-se a recortes como trabalho e economia, podendo desembocar, inclusive, para setores como saúde e educação, mas não se projeta para o esporte e lazer. Assim, pode-se dizer que existe uma lacuna relacionada aos estudos de políticas públicas voltadas para esse setor (SUASSUNA et al, 2007, p.13).
\end{abstract}

Ações intersetoriais têm sido realizadas no contexto do esporte e lazer, embora a tentativa de integração e coletividade no que se diz respeito ao planejamento e à implementação de uma política intersetorial não seja algo simples ou cotidiano. Assim, entendemos que,

\begin{abstract}
Uma proposta intersetorial precisa ter a capacidade de articular os vários campos sociais de um território no trato das demandas a serem atendidas na sua globalidade. Esse desafio implica a compreensão das necessidades socioculturais dos envolvidos nas ações políticas (familiares, escolares, de trabalho, esporte, lazer, cultura, etc) e de como cada ação governamental pode atuar sobre elas. A integração das ações caracteriza-se pela definição de finalidades compartilhadas, estruturadas de forma interdependente e complementar (BONALUME, 2011, p.10).
\end{abstract}

Algumas ações no âmbito do esporte e do lazer em que o modelo intersetorial acontece (mesmo que distante de formas idealizadas) ocorrem pela articulação entre PST e ME, via Programa Mais Educação (PME). Por ele, busca-se a integração entre esporte e educação com o intuito de incentivar a prática esportiva na escola e proporcionar ao aluno condições de intensificar seu campo formativo. A ampliação da experiência esportiva expandiu as políticas esportivas educacionais e de inclusão em atendimento a mais de 1,2 milhões de beneficiados. Contudo, se considerarmos os números apresentados pelo Censo 2010 (BRASIL, 2010a) as escolas públicas de educação básica têm mais de 40 milhões de alunos matriculados, o que nos leva a perceber que será preciso avançar e investir muito ainda para atender cada vez mais essa população, embora seja uma ação a se considerar.

Nessa perspectiva, a escola compromete-se a desenvolver o esporte de acordo com as diretrizes do PST com a implementação no PME, ou seja, as atividades devem 
estar em consonância com a proposta pedagógica e se caracterizarem como "proposta inclusiva e emancipadora" (BRASIL, 2011b), assim designada pelo Ofício Circular 50/2011, que mantém como pressuposto básico o esporte educacional. Porém, atentamos para o fato de que, embora o PST apresente uma proposta educacional, ainda revela uma estrutura de argumentação salvacionista que se torna evidente nos documentos, como observado: “Com essa ação a Educação Brasileira está atendendo a dois aspectos simultaneamente, ou seja, mantém as crianças no espaço escolar com chances de enriquecimento, assim como evita que estas sejam atraídas pelas mazelas das ruas e seus perigos" (BRASIL, 2012a, s/p). Nessa direção, a escola passa a ser vista como local seguro, de aprendizados, enquanto a rua passa a comportar, no imaginário social, todos os riscos e vícios impróprios à formação humana. Ao invés de ser o espaço de retomada do cotidiano urbano, de encontros entre comunitários, com redimensionamento das praças, dos equipamentos de lazer e das relações interpessoais, ambientes que possibilitariam o desenvolvimento da brincadeira e das atividades esportivas, a rua passa a ser local de abandono, marginalidade e desprezo.

A FIG. 2 traz duas variáveis a partir das quais podemos observar quatro tipos de projetos sociais, sendo que o PELC e o PST estão alocados na quarta categoria de política, classificados como projetos de baixa programabilidade e elevada interação com usuários. Notoriamente, nesses projetos, as necessidades ou determinadas situações particulares do receptor guiam os desenhos de suas ações. 


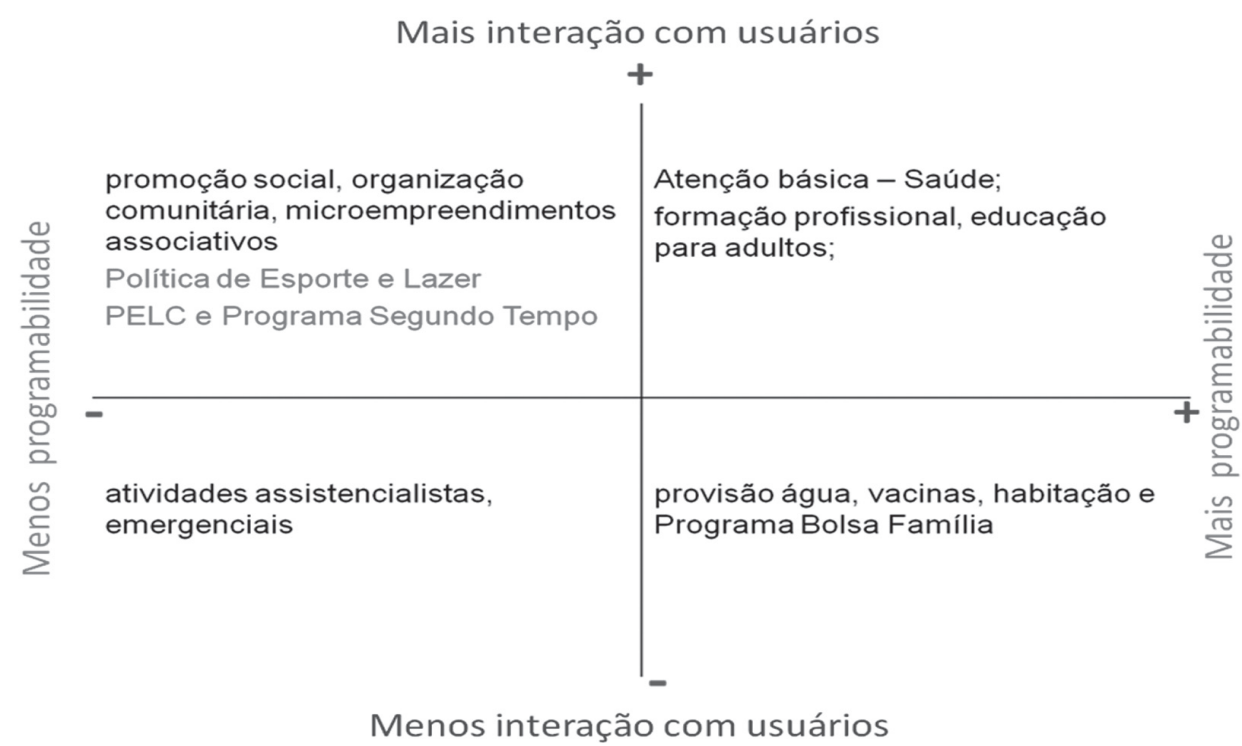

FIGURA 2- Relação entre programabilidade e interação com usuários - Tipologia.

Fonte: Elaborado por Sousa et al (2011, p.48) com base em Nogueira (1998).

Observamos, a partir de Sousa et al (2011), que o PELC possibilita ao operador/gestor maior poder de decisão que os operadores/gestores do PST, o que ocorre devido à natureza dos objetos dos programas (PELC, voltado ao lazer; PST, relacionado ao esporte educacional), haja vista os objetivos propostos pelos Programas.

Os projetos sociais enquadrados nessa categoria dependem de atividades de legitimação tanto dos operadores/gestores quanto dos usuários, cuja participação é crucial para o funcionamento das ações. Além disso, esse tipo de projeto social envolve baixa formalização e rotinização das atividades, contextos técnicos pouco consolidados, alta discricionariedade (poder de decisão) do operador e descentralização das ações (SOUSA et al, 2011, p.48).

O PELC visa democratizar o acesso ao esporte recreativo e ao lazer, com foco em ações educativas. A ideia diretriz de que "o lazer vai tomar conta da cidade e a cidade vai tomar conta do lazer" (BRASIL, 2012b, p.1) passa a expressar parte dessa intencionalidade. O PME, por sua vez, tem por intuito o desenvolvimento de atividades que propiciem a melhoria do ambiente escolar, com direcionamento inicial voltado às escolas com baixo Índice de Desenvolvimento da Educação Básica (IDEB). Assim, o 
PME, cujas Portarias Normativas Interministeriais $\mathrm{n}^{\mathrm{o}} 17$ e $\mathrm{n}^{\mathrm{o}} 19$, de 24 de abril de 2007 congregam ações conjuntas envolvendo MEC, ME, Ministério do Desenvolvimento Social e Combate à Fome (MDS), Ministério de Ciência, Tecnologia e Inovação (MCTI), Ministério do Meio Ambiente (MMA) e a Presidência da República, articula vinte e cinco programas federais numa ação conjunta entre Federação, Estados e Municípios, entre os quais destacamos dois vinculados aos Programas de Esporte e Lazer, o PST e o PELC. No entanto, ressaltamos que ao ser inserido no âmbito escolar, esse programa necessita estar integrado ao Projeto Pedagógico da escola e adaptado à dinâmica social da comunidade.

A articulação entre PST e PME parece ter contribuído para a qualificação de algumas das ações que envolvem esporte e lazer, uma vez que "[...] a integração entre os dois programas amplia possibilidades à medida que não é obrigatório que a escola disponha de infraestrutura esportiva, já que o Mais Educação se vale também de espaços alternativos" (BRASIL, 2012a, s/p). Para além disso, o Programa Segundo Tempo isenta-se de gastos com reforço alimentar à medida que os alunos já recebem a merenda escolar complementada pelo MEC para a permanência em tempo integral na escola. "Com isso foi possível potencializar o número de beneficiados e garantir o acesso ao esporte de forma qualificada, desenvolvendo a proposta pedagógica do PST, articulada com o projeto pedagógico da escola" (BRASIL, 2012a, s/p).

Dados apresentados pelo ME (BRASIL, 2012a) evidenciam ter recebido kits de materiais esportivos, uniformes e materiais de apoio pedagógico todas as escolas que aderiram à fusão dos programas, bem como investimentos na capacitação dos profissionais envolvidos. As escolas conveniadas viabilizaram espaços esportivos próprios ou, de terceiros, para o desenvolvimento das atividades, e responsabilizaram-se 
pela seleção e contratação de monitores para trabalharem com até cinco turmas de aproximadamente trinta alunos por semana.

No campo das políticas públicas, o PRONASCI constitui uma política intersetorial reconhecida por Brasil (2010), embora ainda marcado por um viés pragmático focado na prevenção da violência e da criminalidade a partir do desenvolvimento social, educacional e da consciência de cidadania. O programa é apoiado pelo Sistema Único de Segurança (SUSP) e objetiva a prevenção e a criação de meios para viabilizar a análise da realidade de cada ação, com planejamento de estratégias e identificação dos métodos e mecanismos que serão mais adequados à sua aplicação. No campo das políticas públicas de esporte e lazer, fica clara a necessidade, quando incursionamos por estudos sobre o PELC e o PRONASCI, de estabelecer conexão entre os diversos setores, como elucida o plano de trabalho instituído, em 2007, entre ME, por meio da SNDEL, e Ministério da Justiça (MJ).

\footnotetext{
$\mathrm{Na}$ parceria com o PRONASCI, o PELC pretende ampliar sua implementação, tendo como pré-requisito a intersetorialidade. A integração com diferentes programas sociais (Mulheres da Paz; Protejo; Pontos de Cultura; Pontos de Leitura; Saúde da Família e outros) tem em vista potencializar as ações desenvolvidas, no intuito de promover a democratização do acesso às práticas de esporte e lazer para a populaçãoalvo, pela articulação de ações governamentais e a sociedade civil (BRASIL, 2010, p.25-26).
}

A construção de novos paradigmas possibilitou articulações entre ME e MJ, os quais lançaram seus olhares às políticas públicas intersetoriais, incorporando as ações sociais que auxiliam nas mudanças relacionadas à violência. Nessa busca, surge o desafio da parceria PELC/PRONASCI, uma experiência de intersetorialidade do esporte e do lazer agregadora de conteúdos informativos e pedagógicos que poderão influenciar na produção de conhecimento dessa temática de estudo em nosso país. 
A partir dessas intervenções sociais e pedagógicas novas iniciativas poderão ser implementadas para auxiliar na orientação e encaminhamento de jovens que, algumas vezes, carecem de atenção e estímulo em seu processo de formação e atuação social. Contudo, as configurações estruturais do ME e também de gestão levam a incógnitas acerca da continuidade ou extinção de projetos implementados pela SNDEL, mesmo em meio a um diálogo iniciado com pesquisadores da Rede Cedes e o atual Ministro do Esporte na tentativa de refletir acerca dos desdobramentos de ações atinentes a esse Ministério. Esse momento de incertezas e, consequentemente de crise, torna emblemática a luta pela legalidade e legitimidade das políticas públicas de esporte e lazer no Brasil no intuito de preservar as conquistas já alcançadas e ampliar suas potencialidades no conjunto das políticas intersetoriais.

\section{Considerações finais}

Os apontamentos realizados em relação à agenda pública brasileira, às articulações intersetoriais existentes, bem como às políticas públicas de esporte e lazer, retratam a dificuldade existente em se mobilizar essas ações politicamente. Porém, observam-se avanços nas discussões e implementações de programas federais, principalmente na gestão do Governo Lula, a partir de 2003. Tais avanços, por sua vez, estão condicionados não apenas ao interesse político, mas à necessidade de participação social mais efetiva que também tem se mostrado favorável ao debate e que justifica uma ação continuada perante as novas gerações.

Desse modo, discorrer sobre a intersetorialidade requer olhar para além do que está posto, vislumbrando que essa ação pode ser um caminho à conquista de ampliação dos direitos sociais, uma vez que as políticas públicas necessitam se articular em busca 
de efetividade junto à sociedade. Tal intuito deu-se, nesse ensaio, a partir de incursões históricas e leitura crítica do material selecionado, bem como pelos apontamentos dos entraves políticos que dificultam dadas ações.

Entendemos que existem benefícios sociais em relação à intersetorialidade, uma vez que ela amplia perspectivas em setores como educação, saúde, segurança, com a geração de oportunidades que podem potencializar a vida de inúmeras pessoas, bem como, auxiliar no atendimento das necessidades básicas de subsistência da população. Embora o Estado tenha por base uma gama de ações a serem implementadas durante a gestão pública, as políticas públicas estão relacionadas à demanda social, ou seja, à agenda pública de ações governamentais que, teoricamente, resulta de necessidades básicas de subsistência, isto é, das demandas provenientes da sociedade civil. Entretanto, sabemos que tudo faz parte de jogo de interesses que propicia a criação de um cenário facilitador da crença na ideia de que as demandas externas estejam acontecendo no tocante ao processo de políticas públicas voltadas ao social.

Colocar em prática ações que demandem políticas intersetoriais é uma tarefa difícil devido ao fato dos setores públicos ainda trabalharem isoladamente. Claro que para toda regra há exceções, como nos casos apresentados anteriormente. Há agravantes que vêm dificultar esse processo, como o trabalho fragmentado de todos os ministérios, a pouca participação popular e os procedimentos burocráticos que ainda se esbarram nas questões hierarquizadas dos setores. Mesmo que se tenha uma equipe, tudo é organizado de forma compartimentalizada, pois não há incentivo para uma cultura de cooperação que esteja focada no viés de complementaridade. Há, sobretudo, o caráter reparatório creditado ao esporte como meio para adquirir educação ou segurança e não o seu reconhecimento como bem cultural a ser apropriado pela população e como direito 
social. Em complemento, há o lazer, entendido como supérfluo perante as demais necessidades.

Se entendermos o lazer como mecanismo de emancipação do ser humano, como componente da esfera sociocultural que, por meio de seus mais variados sentidos e significados, possa contribuir no processo de sua autonomia podemos, então, recorrer ao lazer como meio para fortalecer diferentes relações entre setores que não costumam dialogar, mas que encontram no lazer um elo para ações conjuntas.

Como palavras finais, reforçamos a necessidade de que as políticas públicas de esporte e lazer possam ser tema de intensos debates e reflexões por diferentes setores com vistas ao aprimoramento de seu campo de intervenção a partir da deflagração de ações que sejam significativas para os beneficiários, devidamente estruturadas e consolidadas de modo a manter os programas criados independente de partido político e interesses adversos ao que a população apresenta como necessidades e prioridades para uma vida digna e humanitária.

Pensar no lazer como eixo norteador de políticas intersetoriais é conceber a possibilidade do diálogo entre as diferentes áreas e interesses, bem como a efetivação de políticas públicas que não compartimentalizem necessidades, mas as percebam e as captem em totalidade. De limites, já estamos fartos; de possibilidades, estamos faltosos, carentes de reflexão e apoio do poder público, da academia e da sociedade civil para a materialização de políticas intersetoriais que sejam agregadoras e acessíveis numa sociedade que se diz democrática, mas que ainda está distante do exercício pleno da democracia.

\section{REFERÊNCIAS}


AZEVEDO, A. A. de. Análise comparativa das políticas públicas do Ministério da Cultura no período de 1996 a 2005: documentos, discursos e a focalização do lazer. In: AZEVEDO, A. A. de; SUASSUNA, D. (Org.). Política e lazer: interfaces e perspectivas. Brasília: Thesaurus, 2007.

BONALUME C. R. O paradigma da intersetorialidade nas políticas públicas. Licere. Belo Horizonte, v. 14, n. 1, mar/2011.

BRASIL. Aprovação, reprovação e abandono - Ensino Fundamental - Censo 2010. Brasília: Ministério de Educação. Instituto Brasileiro de Geografia e Estátística IBGE.

2010a. Disponível em: http://seriesestatisticas.ibge.gov.br/series.aspxno=9\&op=2\&vcodigo=M101\&t=apr ovacao-reprovacao-abandono-ensino-fundamental-serie. Acesso em: 23 jun. 2012.

BRASIL. Constituição (1988). Constituição da República Federativa do Brasil. Brasília: Senado Federal; Centro Gráfico, 1988.

BRASIL. I Conferência Nacional do Esporte. Documento Final. Brasília: Ministério do Esporte, 2005.

BRASIL. II Conferência Nacional de Esporte: documento final. Brasília: Ministério do Esporte, 2007. (Construindo o Sistema Nacional de Esporte e Lazer).

BRASIL. Política Intersetorial: PELC e PRONASCI. Brasília: Ministério do Esporte Secretaria Nacional de Desenvolvimento de Esporte e de Lazer, 2010.

BRASIL. III Conferência Nacional do Esporte: por um time chamado Brasil. Comissão Nacional de Sistematização - Etapa Nacional. Anais da III CNE. 2010. Brasília: Ministério do Esporte, 2011a.

BRASIL. Ofício Circular 50/2011 - CGAPI/DEEIC/SNEED/ME-GAB/SEB-MEC. Brasília: Ministério do Esporte e Ministério da Educação, $2011 \mathrm{~b}$.

BRASIL. Programa Segundo Tempo no Mais Educação. Brasília: Ministério do Esporte, 2012a. Disponível em: http://www.esporte.gov.br Acesso em: 24 jun. 2012.

BRASIL. Projeto Esporte e Lazer da Cidade - PELC: diretrizes. Brasília: Ministério do Esporte, 2012b. Disponível em: http://www.pst.uem.br. Acesso em: 28 jul. 2012.

BRONZO, C.; VEIGA, L. Intersetorialidade e políticas de superação da pobreza: desafios para a prática. Revista Serviço Social e Sociedade, São Paulo, n. 92, nov. 2007.

CASTELLANI FILHO, L. A educação física no sistema educacional brasileiro: percurso, paradoxo e perspectivas. Tese (Doutorado em Educação). Campinas: UNICAMP/FE, 1999.

CKAGNAZORFF I. B; MELO, J. de S. C. Implementação de programa intersetorial de políticas públicas: o caso de BH cidadania. SEMINÁRIO EM ADMINISTRAÇÃO, 8, EAD-FEA-USP. Anais... 2005. Disponível em: 
http://www.ead.fea.usp.br/Semead/8semead/resultado/trabalhosPDF/328.pdf. Acesso em: 04 ago. 2012.

COMERLATTO, D. et al. Gestão de políticas públicas e intersetorialidade: diálogo e construções essenciais para os conselhos municipais. Revista Katál, Florianópolis, v.10, n.2, p. 265-271, jul./dez., 2007. Disponível em: http://www.scielo.br/pdf/rk/v10n2/a15v10n2.pdf. Acesso em: 30 jul. 2012.

DIAS, D.C; FONSECA, Z. V. D. Esporte e lazer como necessidade humana: inflexões. In: SOARES A. A. et al. Diagnóstico do esporte e lazer na região norte brasileira. Manaus: Edua, 2011.

FILGUEIRA, J. C. M. Gestão de projetos esportivos sociais. In: OLIVEIRA, A. A. B. de; PERIM, G. L. (Org.). Fundamentos pedagógicos do Programa Segundo Tempo: da reflexão à prática. Maringá: Eduem, 2009. p.13-30.

GOMES, A. de T. Nation-building e segurança internacional: Um debate em construção. Contexto Internacional, Rio de Janeiro, v.31, n.2, mai/ago., 2009.

GOULART, M. A. A intersetorialidade no contexto da educação integral. Educação integral. Educação Integral. Salto para o futuro. v. 18, n. 13, ago. 2008.

HASSENPFLUG, W. N. Educação pelo esporte: educação para o desenvolvimento humano pelo esporte. São Paulo: Saraiva/Instituto Ayrton Senna, 2004.

Intersetorialidade, transetorialidade e redes sociais na saúde. Revista Brasileira de Administração Pública, Rio de Janeiro, v. 34, n. 6, p. 35-45, nov./dez., 2000

- A gestão intersetorial das políticas sociais e o terceiro setor. Revista Saúde e Sociedade. São Paulo, v. 13, n. 1, p. 25-36, jan/abr., 2004.

KNOPP, G. da C. Cultura e desenvolvimento local: um estudo do programa BairroEscola da cidade de Nova Iguaçu. Dissertação (Mestrado em Administração Pública). Fundação Getúlio Vargas. Escola Brasileira de Administração Pública e de Empresas. Centro de Formação Acadêmica e Pesquisa da Fundação Getúlio Vargas. Rio de Janeiro, 2008.

MEIRELLES, B. H. S.; ERDMANN, A. L. Redes sociais, complexidade, vida e saúde. Ciência, Cuidado \& Saúde. Maringá, v. 5, p. 67-74, jan./abr. 2006.

MELO, M. A. As sete vidas da agenda pública brasileira. In: RICO, E. M. (Org.). Avaliação de políticas sociais: uma questão em debate. 6. ed. São Paulo: Cortez, 1998.

PINTO, L. M. S. M. et al. O lazer. In: . et al (Org.) Brincar, jogar, viver: lazer e intersetorialidade com o PELC - Brasília: Ideal, 2011.

PRONI, M. W. A metamorfose do futebol. Campinas: UNICAMP, IE, 2000. 
SCHARTZ, G. M. et al. Gestão da informação: sobre esporte recreativo e lazer: balanço da Rede Cedes. Várzea Paulista: Fontoura, 2010.

SOUSA, E. S. de. et al. Sistema de monitoramento e avaliação dos programas Esporte e Lazer da Cidade e Segundo Tempo do Programa do Ministério do Esporte. Belo Horizonte: Ideal, 2011.

SOUZA, C. Políticas públicas: uma revisão de literatura. Revista Sociologias, Porto Alegre, ano 8. n.16, jul./dez., 2006. p. 20-46.

SOUZA, D. S. de. Do bom e do melhor: o consumo de bens de luxo por uma nova classe. Dissertação de Mestrado. Rio de Janeiro: Fundação Getúlio Vargas, 2011.

STAREPRAVO, F. A. Políticas públicas de esporte e lazer no Brasil: aproximações, intersecções, rupturas e distanciamentos entre os subcampos político/burocrático e científico/acadêmico. Tese (Doutorado) Curitiba/Brasil: UFPR, 2011.

SUASSUNA, D. et al. O ministério do esporte e a definição de políticas para o esporte e lazer. In: F. de A, AZEVEDO A. A. de. Política e lazer: interfaces e perspectivas. Brasília: Thesaurus, 2007. p.13-42.

TUBINO, M. Estudos brasileiros sobre o esporte: ênfase no esporte-educação. Maringá: Eduem, 2010. Disponível em: http://www.defesasocial.al.gov.br/planos-esistemas/sistema-unico-de-seguranca-publica. Acesso em: 28 nov. 2011.

\section{Endereço dos Autores}

Sandra Aparecida Zotovici

Universidade Estadual de Maringá

Avenida Colombo, 5790, Bloco 06, sala 12

Jardim Universitário - Maringá - Paraná - Brasil

CEP 87020-900

Endereço Eletrônico: zotovici@hotmail.com 